\title{
ASSESSMENT OF PRIMARY AIR POLLUTANTS IN A TROPICAL METROPOLITAN REGION BY COMBINING LOCAL AND GLOBAL EMISSIONS INVENTORIES
}

\author{
YASMIN KAORE LAGO KITAGAWA ${ }^{1}$, ERICK GIOVANI SPERANDIO NASCIMENTO ${ }^{2}$, \\ LÍLIAN LEFOL NANI GUARIEIRO ${ }^{2}$, TACIANA TOLEDO DE ALMEIDA ALBUQUERQUE ${ }^{1,3}$ \\ \& DAVIDSON MARTINS MOREIRA ${ }^{1,2}$ \\ ${ }^{1}$ Federal University of Espírito Santo (UFES), Brazil \\ ${ }^{2}$ Manufacturing and Technology Integrated Campus (SENAI CIMATEC), Brazil \\ ${ }^{3}$ Federal University of Minas Gerais (UFMG), Brazil
}

\begin{abstract}
The community multiscale air quality (CMAQ) model was evaluated in the metropolitan region of Salvador (MRS), which is the capital of the state of Bahia, Brazil. Once located at the tropics, two episodes were selected (one in the dry season and another in the rainy season), in order to perform the assessment. The meteorological information required for air quality modeling was driven by the weather research and forecasting (WRF) model: its performance was evaluated against observational data collected by monitoring stations located in Salvador city, Brazil. For the emissions inventory, we applied the Emissions Database for Global Atmospheric Research (EDGAR), in conjunction with an estimated emissions inventory of local point sources located in the major industrial complexes, in addition with the biogenic emissions estimated by the model of emissions of gases and aerosols from nature (MEGAN). To compute these different emissions sources, we used the sparse matrix operator kernel emission (SMOKE). Following that, the CMAQ model was applied, in order to simulate the chemical transport and formation of air pollutants based on the meteorological and emissions input previously described. The required boundary conditions were determined by also applying the CMAQ model, which used data from the MEGAN and EDGAR inventories, to a larger domain that incorporates the domain in which the MRS is represented. The application of these modeling tools was shown to be a good practice in the assessment of air quality in urban areas; thus, this work aims to be the first great effort to study, simulate and validate the chemical transport of pollutants over the MRS, based on a hybrid emissions inventory and using the state of the art in the computational atmospheric modeling field.
\end{abstract}

Keywords: Brazil, WRF, SMOKE, CMAQ, EDGAR, MEGAN, comparative emissions, emissions inventory, air quality.

\section{INTRODUCTION}

Despite the efforts put into practice in seeking for strategies and actions that contribute to the improvement of air quality in Brazil, there is a scarcity of information that is still a troublesome, which counts with only $1.7 \%$ of coverage of Brazilian cities by air monitoring systems [1], and most of these cities count with a single station for monitoring a whole urban region. Beyond that, several regions of South America face serious deficiencies in local emission data, measurement campaigns, and the application of air quality models [2] that are critical for generating information; and consequently, to have a better understanding of the air quality status of Brazil.

The Brazilian legislation was updated through resolution number 491/2018 [3], which sets new air quality standards with intermediate and progressive goals, until reaching the final standard suggested by the World Health Organization (WHO).

We can say that a first step was taken towards stricter public policies, that can probably lead us to an improvement in the air quality in Brazil. As we know, air quality management is based on a proper site diagnosis that involves a reliable description of the initial atmosphere 
and boundary conditions, the representation of land use, the coverage of changes, and the development of an emissions inventory; however, even with a great lack of information of air quality from meteorological stations, radiosondes, radars, an emissions inventory, particulate matter speciation, etc. The endeavour to understand the atmospheric chemical conditions over industrialized Brazilian cities has been done by employing different approaches and methodologies to estimate and generate these pieces of information. Thus, different chemical transport models (CTMs) and also input data are being used in air quality assessment. In addition, CTMs can cover larger regions, when compared with the performance of air monitoring stations that have specific time-space scales and can be economically inviable to be implemented over vast areas like Brazil.

Most studies focus on urban-industrial areas located in the Brazilian south-southeast regions [4]-[8]; while almost none have addressed the other parts of Brazil, such as the northeast region, where there had been a boom in industrial activities and growth in population, over the last decades. Therefore, one of the objectives of the present work was to employ the best practices seen in others' work that employ CTMs to comprehend the local air pollution over the Metropolitan Region of Salvador (MRS). For that, the WRF-SMOKECMAQ modeling system was used to assess the chemical transport of air pollutants (like $\mathrm{SO}_{2}$, $\mathrm{CO}, \mathrm{NO}_{2}$ ) over the MRS during two different seasons, dry and rainy, based on a hybrid emissions inventory applying a local inventory in conjunction with the global inventories called EDGAR and MEGAN, and to compare these modeling results with the observed air quality data from six monitoring stations located within the region.

\section{METHODOLOGY}

\subsection{Study area description}

In our study area, there have been no quantitative studies yet that evaluate the use of CTMs through observational data over the MRS. In addition, there was also no application of inventories that could account for different emission sources, as well as the chemical transport of air pollutants from other regions. MRS is an urban-industrial and costal area, located in the state of Bahia in the north east of Brazil, formed by 13 cities with a total population of over 4 million inhabitants. Beyond the activities related to tourism and commerce, which play a very important role in the region's economy, this area also counts with several industries, such as: petrochemical, automotive, metallurgical and construction, whose activities and major companies are displayed in Fig. 1.

The Cristal factory manufactures chemical products, including titanium dioxide and sulfuric acid, that are used in the paint, paper, plastic bottle, vinyl siding and packaging materials industries. The Camaçari Industrial Complex (CIC) includes producers of petrochemical products that are used to make thermoplastic resins, fertilizers and copper metallurgy, among others.

The Aratu Industrial Center (CIA), with its operation covering the areas of Salvador, Simões Filho and Candeias counties, is a multisectoral industrial complex that has several enterprises: chemical segments, footwear, food, metallurgy, furniture, plastics, fertilizers, electronics, beverages and textiles; and the Landulpho Alves Refinery (RLAM), in São Francisco do Conde and Madre de Deus counties, which belongs to Petrobrás S.A. and is also a petrochemical complex.

To distinguish seasonal differences in the MRS, we analyzed the observed data for precipitation rainfall. Then, we selected two periods: a dry one (from 16 January-15 February) and a rainy one (23 June-23 July) within the year 2015, totaling 30 days for each 

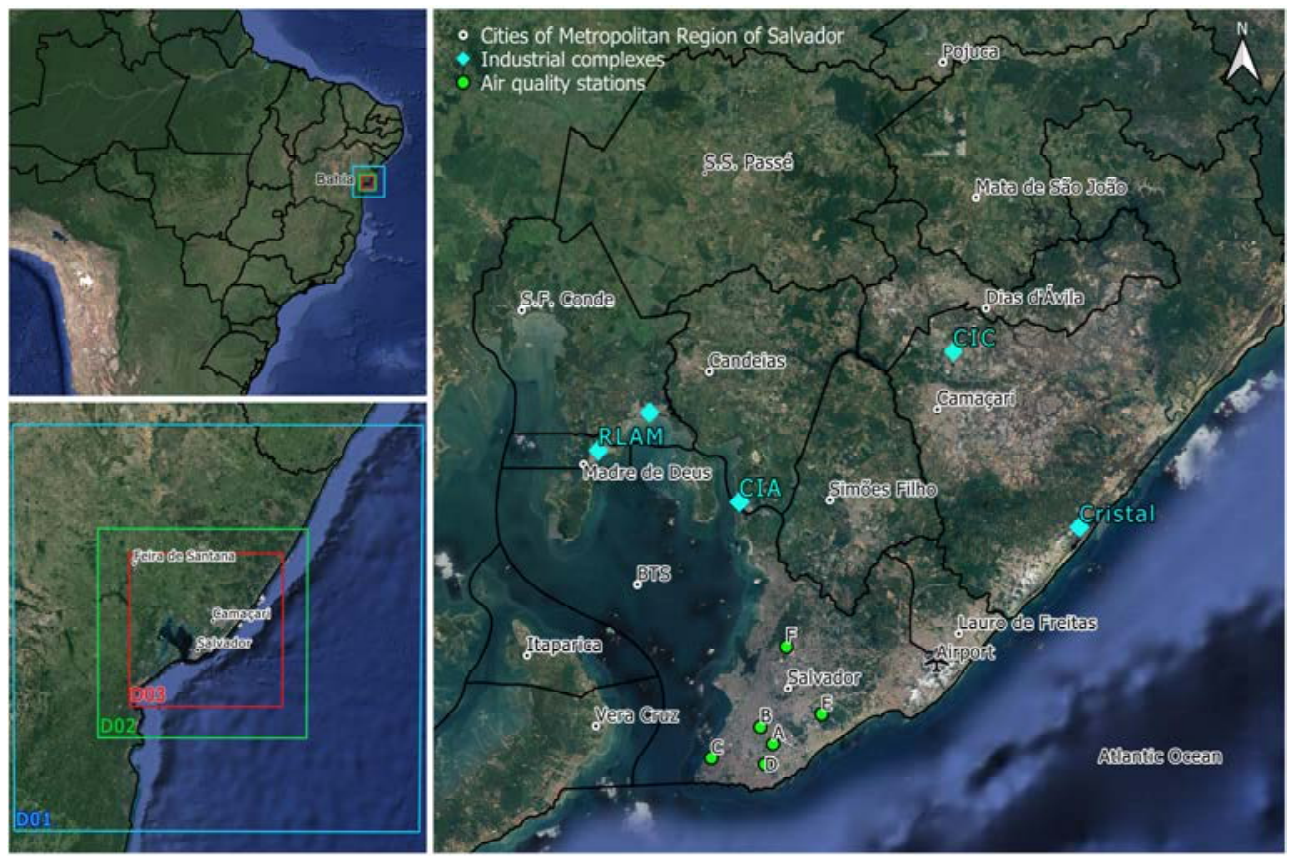

Figure 1: The location of Bahia state in Brazil (upper left), and the domains used in the configuration of the meteorological and photochemical models (lower left). The major industrial complexes (cyan diamonds), and the air quality stations (green dots) are shown within the MRS.

period of analysis. Both periods comprise part of a vacation period in which vehicle emissions may differ substantially and influence air pollutant concentrations; however, it is worth mentioning that vehicular emissions were not accounted for in this work.

\subsection{Setup of the WRF model}

The meteorological fields were generated by the WRF model [9], version 3.9.1. Its outputs were used by the MCIP model, in order to create input data that are needed by SMOKE and by CMAQ. A brief description of the spatial and physical configuration of the WRF model is given below.

The initial and boundary conditions came from the GDAS/FNL operational model global tropospheric analyses data set [10], available at a resolution of 0.25 degrees every 6 hours. The land use data were provided by the US Geological Survey at $5 \mathrm{~min}, 2 \mathrm{~min}$ and $30 \mathrm{~s}$ resolutions. We used three nested domains with a $9 \mathrm{~km}(39 \times 39$ cells $), 3 \mathrm{~km}(60 \times 60$ cells $)$, and $1 \mathrm{~km}$ grid resolution $(132 \times 132$ cells), as shown in Fig. 1, with 23 vertical levels with the model's top one set at $50 \mathrm{hPa}$. The physical configurations adopted were: Lin microphysics, Eta similarity surface layer scheme, Mellor-Yamada-Janjić planetary boundary layer scheme, Grell-Devenyi cumulus parametrization, Dudhia shortwave radiation, Rapid Radiative Transfer Model longwave radiation and the Noah land-surface model. Even though WRF performance in this study had reasonably good agreement between the observed and simulated data for the dry and rainy periods, it was decided not to show the hourly variation 
plots and statistical metrics of this WRF performance, since detailed evaluation of the WRF model results to the MRS can be found in previous studies [11].

\subsection{Hybrid emissions inventory details}

To build the hybrid emissions inventory, we used information from EDGAR, MEGAN, and a local estimated emission inventory based on point sources. SMOKE, which is an emissions processor used by CMAQ, was prepared to run for the coarse domain (D01) and the domain of interest (D03) for Fig. 1. The EDGAR and MEGAN data was applied in the D01, in order to generate boundary conditions for the D03.

The EDGAR is a global inventory [12] that contains annual emissions of greenhouse gases and air pollutants from 1970 to 2012. We used the newest version, 4.3.2 (https://cidportal.jrc.ec.europa.eu/ftp/jrc-opendata/EDGAR/datasets/v432_AP/), with a spatial resolution of 0.1 degree. Datasets for $\mathrm{CO}, \mathrm{NO}_{\mathrm{x}}, \mathrm{NMVOC}, \mathrm{NH}_{3}, \mathrm{SO}_{2}, \mathrm{BC}, \mathrm{OC}, \mathrm{PM}_{10}$, $\mathrm{PM}_{2.5}$ with base year of 2012 were used (the closest year to 2015).

The MEGAN is a global model used to estimate fluxes of biogenic compounds, between terrestrial ecosystems and the atmosphere, that can be used for regional air quality modeling and global earth system modeling studies [13]. In this study, MEGAN version 2.04 was run in an offline mode, which means that the MEGAN driving variables used meteorology and land cover data from WRF to provide emissions in a format that is suitable for the SMOKE processor.

As there is no official emission inventory for the MRS, we used other's work to build the local inventory [14], with estimated emission rates for $\mathrm{SO}_{2}, \mathrm{NO}_{\mathrm{x}}$ and $\mathrm{CO}$ based on data of consumption, fuel composition, type of boiler/furnace, hours of operation per year and oil/gas density. The emission factors were taken from US EPA AP-42 guidelines. Again, because of the absence of full information about the other source types in his work, we decided to count only the point sources category, which information about latitude-longitude coordinates and stack parameters (e.g. stack height and diameter, exit gas velocity, exit gas temperature. Thus, we used information from 42 companies located at CIC and RLAM (Fig. 1), numerating 203 point sources, which were only computed in the D03.

\subsection{Setup of CMAQ model}

The chemical transport model CMAQ [15] version 5.2.1 was applied in this study. To promote the assessment of air quality, information about meteorology, emissions, and initial (IC) and boundary conditions (BC) were necessary. The BC used by the $\mathrm{D} 01$ were a default setup of the BCON processor and had static concentrations. The BC used by the D03 were generated by the simulations performed with D01, and had time-dependent concentrations. The IC for both domains had static concentrations and were also estimated by the CB05 gas mechanism with sixth-generation to aerosol, also an option in ICON processor. The temporal profiles used to convert the annual emissions estimated [14] to hourly emissions were defined uniformly over time. The spatial resolution comes from the WRF settings. The chemical speciation of $\mathrm{NO}_{\mathrm{x}}$ was of $95 \% \mathrm{NO}$ and $5 \% \mathrm{NO}_{2}$, as previously suggested [16]. The CMAQ configurations are summarized in Table 1.

The performance of the CMAQ model was done by comparing the hourly observed data from six different stations located in Salvador city (to be found at (a) Avenue ACM; (b) Barros Reis; (c) Campo Grande; (d) Itaigara; (e) Paralela; and (f) Pirajá in Fig. 1). Despite that the air quality monitoring network of the MRS has been operating since 2013, it is still limited in its spatial coverage and lacks detailed information. We calculated the statistical 
Table 1: Spatial and physical configuration of the CMAQ model.

\begin{tabular}{lll}
\hline Domain & Dry period & Rainy period \\
\hline Initial date & 15 Jan. 2015 (00 UTC) & 22 Jun. 2015 (00 UTC) \\
\hline Final date & 23 Feb. 2015 (06 UTC) & 23 Jul. 2015 (06 UTC) \\
\hline Grid resolution & $1 \mathrm{~km}$ & \\
\hline Column and row numbers & $130 \times 130$ \\
\hline Chemical mechanism of the IC & cb05e51_ae6_aq (used in D01 and D03 domains) \\
\hline Chemical mechanism, BC-D01 & cb05e51_ae6_aq (default setup) \\
\hline Chemical mechanism, BC-D03 & Outputs of simulations run with D01 \\
\hline Chemical mechanism, CCTM & cb6r3_ae6_aq \\
\hline
\end{tabular}

metrics of the observed mean (OBS), modeled mean (MOD), root mean square error (RMSE), normalized mean bias (NMB) and correlation coefficient (r). Graphical plots of the mean hourly variation comparing the observed and modeled $\mathrm{SO}_{2}, \mathrm{CO}$ and $\mathrm{NO}_{2}$ concentrations in both the dry and rainy period at each station were also presented, in order to aid in the models' performance evaluation. All plots are presented given the local time and were generated by Python packages found within the Google Earth program.

\section{RESULTS AND DISCUSSION}

\subsection{Sulfur dioxide $\left(\mathrm{SO}_{2}\right)$ concentrations}

The mean observed $\mathrm{SO}_{2}$ concentrations presented values approximately up to1 $\mathrm{ppb}$, with seasonal differences between dry and rainy periods being hardly seen; however, the dry period showed values a bit higher than the wet period in hourly variation. We noted that there were slight changes in the observed $\mathrm{SO}_{2}$ concentrations at 6 a.m., in the dry period at Itaigara station (Fig. 2(d)); and also at 11-12 h at the Barros Reis station (Fig. 2(b)). The lowest difference of mean observed $\mathrm{SO}_{2}$ concentrations between the dry and rainy periods was seen at Pirajá station (Table 2 (ID f)). Among the others, the dry period presented average values that were higher than twice those of the wet period, except for the Barros Reis station (Table 2 (ID b)). By comparing with the Brazilian air quality standards, we found that the observed $\mathrm{SO}_{2}$ was far from the limit established by the environmental council (which is $7 \mathrm{ppb}$ for a $24 \mathrm{~h}$ mean); the limits were up to the value of $2 \mathrm{ppb}$, i.e. they did not exceed critical levels. It was expected that there would be larger observed $\mathrm{SO}_{2}$ concentrations, due to the presence of considerable vehicular fleet activity and also because of many sources from petrochemical activities.

The CMAQ model has overestimated all $\mathrm{SO}_{2}$ concentrations, except in the first hours of the morning, between midnight and 3-4 a.m., in some sites. The largest discrepancies occurred especially at 6 and 7 a.m. within the rainy and dry period, respectively.

The increasing $\mathrm{SO}_{2}$ concentrations were shown by all stations for the wet period (around 3 a.m.), and in the dry period (with a time lag of $1 \mathrm{~h}$ ). These peaks observed in the mean modeled $\mathrm{SO}_{2}$ data are maybe most probably caused by industrial chimneys represented in the local inventory, since the maximum values produced by local $\mathrm{SO}_{2}$ were about seven times greater than the maximum values estimated by the EDGAR inventory (MEGAN does not estimate $\mathrm{SO}_{2}$ concentrations as input data). Because local inventory is the major contributor 


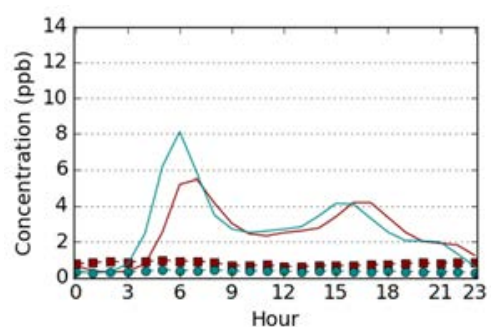

(a)

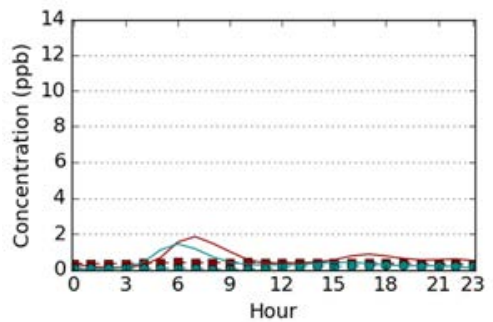

(c)

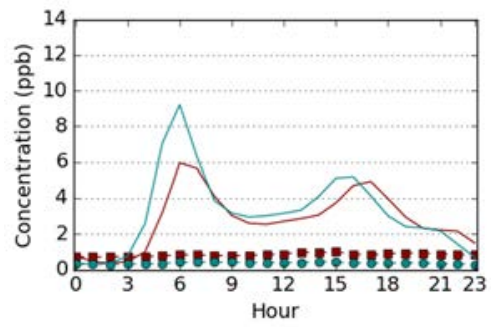

(e)

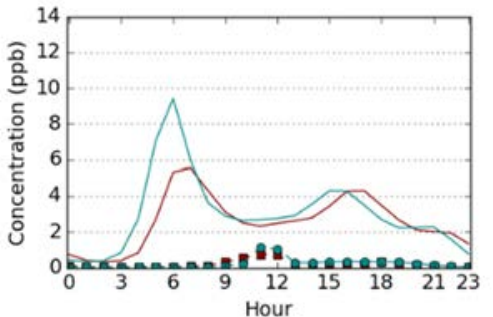

(b)

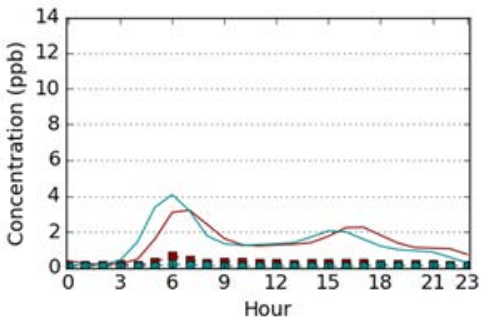

(d)

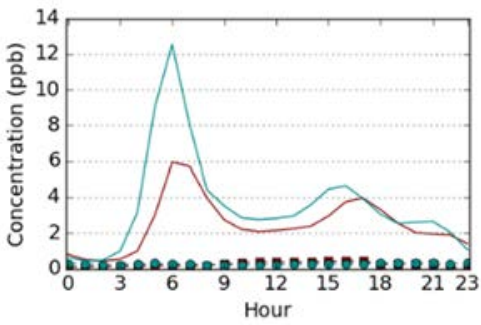

(f)

Observed-dry - Modeled-dry $\bullet$ Observed-wet - Modeled-wet

Figure 2: Comparison of mean hourly variation of the modeled (solid lines) and observed (dashed lines) $\mathrm{SO}_{2}$ concentrations at the following stations. (a) ACM; (b) Barros Reis; (c) Campo Grande; (d) Itaigara; (e) Paralela; and (f) Pirajá.

Table 2: Statistics comparing modeled and observed $\mathrm{SO}_{2}$ for each air quality station, in ppb units.

\begin{tabular}{ccccccccccc}
\hline \multirow{2}{*}{ ID } & \multicolumn{2}{c}{ OBS } & \multicolumn{2}{c}{ MOD } & \multicolumn{2}{c}{ RMSE } & \multicolumn{2}{c}{ NMB } & \multicolumn{2}{c}{ r } \\
\cline { 2 - 11 } & Dry & Wet & Dry & Wet & Dry & Wet & Dry & Wet & Dry & Wet \\
\hline a & 0.79 & 0.35 & 2.51 & 2.78 & 2.39 & 3.33 & 2.19 & 6.86 & 0.03 & 0.02 \\
\hline b & 0.18 & 0.23 & 2.58 & 3.00 & 2.88 & 3.91 & 13.10 & 12.28 & 0.08 & 0.01 \\
\hline c & 0.37 & 0.13 & 0.64 & 0.39 & 0.73 & 0.91 & 0.68 & 1.98 & 0.11 & -0.01 \\
\hline d & 0.24 & 0.10 & 1.40 & 1.40 & 1.44 & 1.85 & 4.77 & 12.82 & 0.35 & 0.25 \\
\hline e & 0.83 & 0.37 & 2.80 & 3.21 & 2.64 & 3.93 & 2.36 & 7.76 & 0.07 & 0.05 \\
\hline f & 0.24 & 0.26 & 2.47 & 3.55 & 2.74 & 4.82 & 9.26 & 12.54 & 0.04 & 0.01 \\
\hline
\end{tabular}

ppb: parts per billion; $\mathrm{SO}_{2}$ : Sulfur dioxide. 
to $\mathrm{SO}_{2}$ emissions, we can say that the emissions factors of AP-42 were assumed [14], inducing the overestimation of $\mathrm{SO}_{2}$ emissions rates. Beyond that, the temporal profiles were assumed to be uniform over time.

The mean modeled $\mathrm{SO}_{2}$ concentrations were higher during the rainy period than the dry period, except for the Campo Grande station (Table 2 (ID c)); however, overall, the hourly variation of modeled results presented almost the same behavior in the different sites of Salvador city, with the peaks occurring during rush hours, even though mobile sources were not accounted for in the local inventory. The highest errors were most associated with the rainy season, showing the great dependence of the CTMs on the meteorological model results.

All sites had very poor values of correlation coefficient: the highest one was shown by Itaigara $\left(r_{\text {dry }}=0.35 ; r_{\text {wet }}=0.25\right)$. Campo Grande had the lowest errors in statistical indexes, while the others presented almost the same error values.

\subsection{Carbon dioxide $\left(\mathrm{CO}_{2}\right)$}

The seasonal differences of mean observed $\mathrm{CO}_{2}$ concentrations were noted at the Barros Reis and Paralela stations (Fig. 3(b) and (e)); however, they had the inverse behavior of the highest values. Seasonal variation was slightly different among the others stations. The observed $\mathrm{CO}_{2}$ concentrations' limits were up to $1 \mathrm{ppm}$ in the dry period and up to $2 \mathrm{ppm}$ in the rainy season, which means it did not reach the value of 9 ppm, established by the Brazilian air quality council. The mean diurnal variation in both periods was more prominent than the results presented for $\mathrm{SO}_{2}$. The peaks of observed $\mathrm{CO}_{2}$ occurred in the beginning of the morning (6-7 a.m.) and in the late afternoon (at $18 \mathrm{~h}-19 \mathrm{~h}$ ).

The CMAQ model has clearly underestimated two sites (Fig. 3(b) and (c)); however, the behavioral changes of the diurnal variations were captured by the model, meaning that the CMAQ model showed a better agreement for $\mathrm{CO}_{2}$ results. The peaks of mean modeled $\mathrm{CO}_{2}$ also may be or are probably caused by the industrial chimneys that are represented in the local inventory, as the maximum values produced by local $\mathrm{CO}_{2}$ were about three times greater than the maximum values estimated by the EDGAR inventory. In the MEGAN estimate, we found almost no $\mathrm{CO}_{2}$ concentrations (with values around 0.05 to $0.1 \mathrm{moles} / \mathrm{s}$ of $\mathrm{CO}_{2}$ ). By the way, all species data provided by MEGAN had concentrations values close to zero, with the dry season yielding twice as much an amount as the rainy season. Inversely, EDGAR provided higher concentrations during the rainy season.

Table 3 presents the statistical metrics calculated for $\mathrm{CO}_{2}$ results. The mean observed $\mathrm{CO}_{2}$ concentrations between both periods were similar, except for Barros Reis, where $\mathrm{CO}_{2}$ concentrations were $60 \%$ higher during the rainy season; and at Paralela, where $\mathrm{CO}_{2}$ concentrations were double during the dry period. Mean modeled $\mathrm{CO}_{2}$ concentrations were virtually identical for both periods, as well as the statistical errors, but with slight variations. The correlation coefficient values for $\mathrm{CO}_{2}$ were higher than $\mathrm{SO}_{2}$ values, indicating a better agreement for this pollutant.

\subsection{Nitrogen oxides $\left(\mathrm{NO}_{\mathrm{x}}\right)$}

The analyses of $\mathrm{NO}_{\mathrm{x}}$ results were made though the assessment of $\mathrm{NO}_{2}$ concentrations, since only the air monitoring stations provide this kind of data. Despite that, the daily variation of observed $\mathrm{NO}_{2}$ presented a similar behavior to $\mathrm{CO}_{2}$, with the maximum occurring in the early morning (from 6-7 a.m.), decreasing during the day, and increasing again in the late afternoon. Another finding was that, unlike the $\mathrm{SO}_{2}$ and $\mathrm{CO}_{2}$ results, the $\mathrm{NO}_{2}$ concentrations 


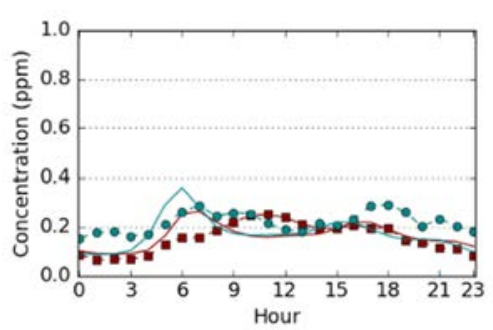

(a)

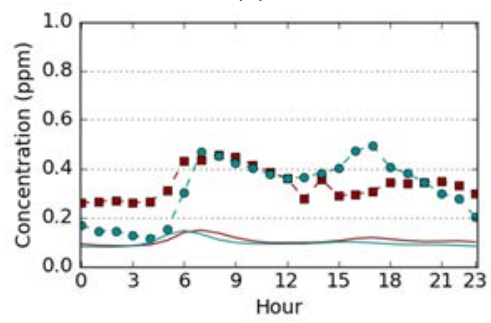

(c)

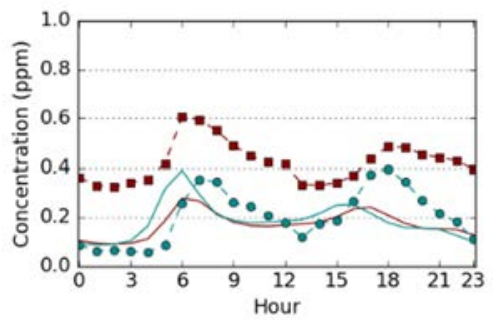

(e)

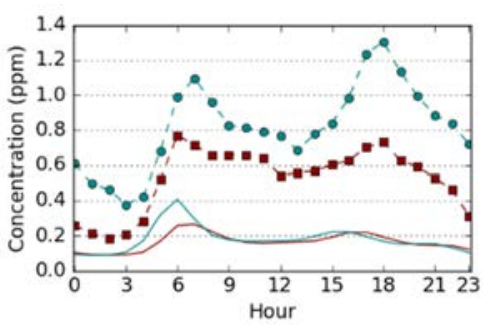

(b)

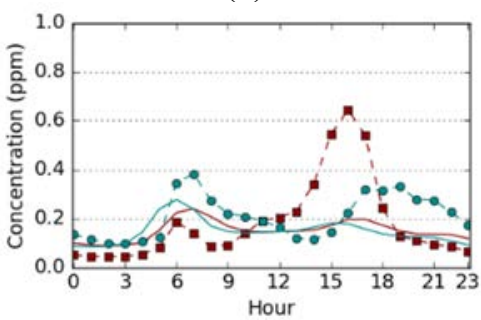

(d)

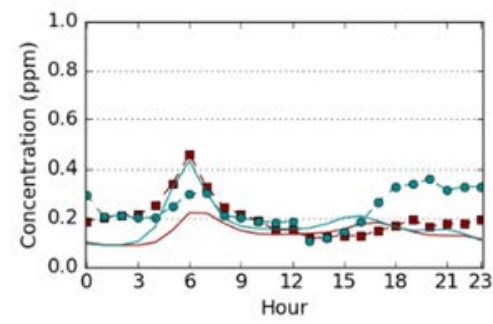

(f)

Observed-dry

Modeled-dry

Observed-wet

Modeled-wet

Figure 3: Comparison of mean hourly variations of modeled (solid lines) and observed (dashed lines) $\mathrm{CO}_{2}$ concentrations at the monitoring stations in: (a) ACM; (b) Barros Reis; (c) Campo Grande; (d) Itaigara; (e) Paralela; and (f) Pirajá.

Table 3: Statistics comparing modeled and observed $\mathrm{CO}_{2}$ in ppm for each air quality station.

\begin{tabular}{ccccccccccc}
\hline \multirow{2}{*}{ ID } & \multicolumn{2}{c}{ OBS } & \multicolumn{2}{c}{ MOD } & \multicolumn{2}{c}{ RMSE } & \multicolumn{2}{c}{ NMB } & \multicolumn{2}{c}{ r } \\
\cline { 2 - 11 } & Dry & Wet & Dry & Wet & Dry & Wet & Dry & Wet & Dry & Wet \\
\hline a & 0.16 & 0.22 & 0.16 & 0.17 & 0.14 & 0.18 & 0.05 & -0.21 & 0.19 & 0.19 \\
\hline b & 0.52 & 0.82 & 0.16 & 0.18 & 0.41 & 0.76 & -0.69 & -0.78 & 0.68 & 0.32 \\
\hline c & 0.34 & 0.32 & 0.11 & 0.10 & 0.32 & 0.32 & -0.69 & -0.70 & 0.23 & 0.23 \\
\hline d & 0.18 & 0.21 & 0.15 & 0.15 & 0.24 & 0.24 & -0.18 & -0.29 & 0.31 & 0.16 \\
\hline e & 0.42 & 0.20 & 0.17 & 0.18 & 0.27 & 0.20 & -0.60 & -0.09 & 0.48 & 0.23 \\
\hline f & 0.20 & 0.24 & 0.14 & 0.18 & 0.18 & 0.25 & -0.30 & -0.27 & 0.14 & 0.08 \\
\hline ppm units: parts per million & & & & & & & &
\end{tabular}

ppm units: parts per million. 
were significantly different between seasons: the lowest difference was seen in Itaigara station $\left(\mathrm{Obs}_{\mathrm{dry}}=8.03 \mathrm{ppb} ; \mathrm{Obs}_{\mathrm{wet}}=10.31 \mathrm{ppb}\right)$. The rainy season exhibited higher $\mathrm{NO}_{2}$ concentrations than the dry season, and that was probably caused by the increase of emissions. Paralela station (Fig. 4(e) and Table 4 (ID e)) was the only station that did not present this behavior, most likely because it is located on an important route of vehicular traffic for Salvador city; hence, the concentrations measured at this station are directly influenced by traffic congestion.

The observed time series showed $\mathrm{NO}_{2}$ concentrations varying up to $30 \mathrm{ppb}$ in the dry season (with some peaks between $40-50 \mathrm{ppb}$ ); and reaching up to $40 \mathrm{ppb}$ in rainy period (with some peaks between 50-70 ppb). In any case, the air quality standard (which is set at $100 \mathrm{ppb}$ for $1 \mathrm{~h}$ mean) was not exceeded in either of both periods.

The CMAQ model captured the diurnal variation of $\mathrm{NO}_{2}$; though the increase in the late afternoon was underestimated, especially during the wet period. The peaks of modeled $\mathrm{NO}_{2}$ values again were provided by the local inventory, which presented the maximum $\mathrm{NO}_{2}$ values about fifteen times greater than the maximum values estimated by EDGAR during the dry season (and thirteen times the values in the rainy period). Although knowing that biogenic sources can contributor to $\mathrm{NO}_{\mathrm{x}}$ emissions, the MEGAN inventory estimated no quantities of $\mathrm{NO}_{2}$. This is due to the fact that most of the $\mathrm{NO}_{\mathrm{x}}$ emissions to the atmosphere in it was set up in the form of NO. Even so, the NO concentrations generated by MEGAN had low values, when compared to local and EDGAR inventories. Overall, the $\mathrm{NO}_{2}$ results provided by the CMAQ model seemed to agree a little better with the monitoring stations, when qualitatively compared to the other pollutants $\left(\mathrm{CO}_{2}\right.$ and $\left.\mathrm{SO}_{2}\right)$.

Table 4 shows that the mean modeled $\mathrm{NO}_{2}$ concentrations were virtually similar for both periods; however, the statistical errors were found to be greater in the rainy season and the correlation coefficient values were lower. These discrepancies are associated with the high concentrations of $\mathrm{NO}_{2}$ that were recorded during the rainy period.

\section{CONCLUSIONS}

To the best of our knowledge, there have not yet been any studies evaluating air pollutants $\left(\mathrm{SO}_{2}, \mathrm{CO}_{2}\right.$, and $\left.\mathrm{NO}_{2}\right)$ measured at surface of the MRS, using the WRF-SMOKE-CMAQ modeling system, nor combining different approaches of emission inventories.

Regarding the inventories, the data that came from MEGAN had values close to zero, meaning that it did not significantly contribute to the emissions rates read by the CMAQ model. Despite this, the EDGAR inventory provided slight concentrations, which were much lower than the local inventory, and it seemed not to have correctly represented the spatial distribution of the emissions (e.g. where one of the biggest petrochemical complexes exists in Latin America, the CIC, there is no representation of one of the most important primary air pollutants. The local inventory only has counted with industrial point sources, missing the representation of other types of sources. Therefore, we found nothing more appropriate than the development of the fully local emissions inventory for MRS.

Seasonal differences of the observed data between dry and rainy periods were quite difficult to note, this may be associated with the fact that the seasons in the tropics are not very well defined, such as they are in the middle latitudes/temperature climate zones. Important meteorological variables, such as the temperature and water vapor content that influence chemical reactions in the atmosphere do not present significant changes between both periods, so consequently, to the environmental conditions over the MRS. Beyond the meteorological conditions, we also can say that the emission rates of these air pollutants did not noticeably change between both periods. Regardless, the air quality standards established by the Brazilian environment council were not overtaken by them. 


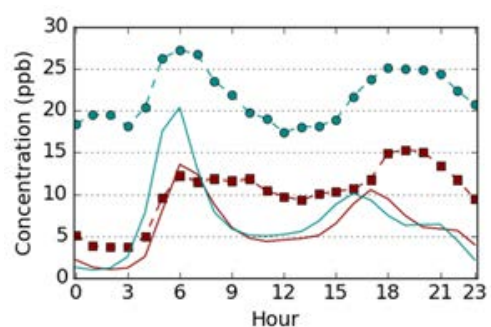

(a)

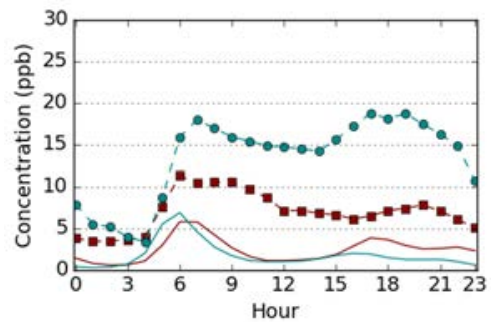

(c)

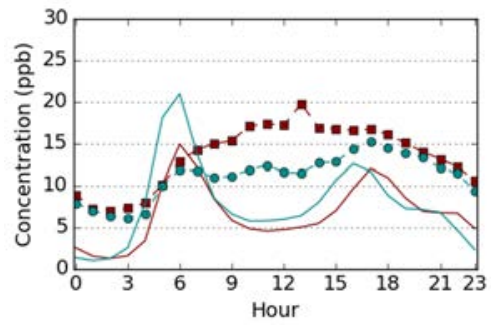

(e)

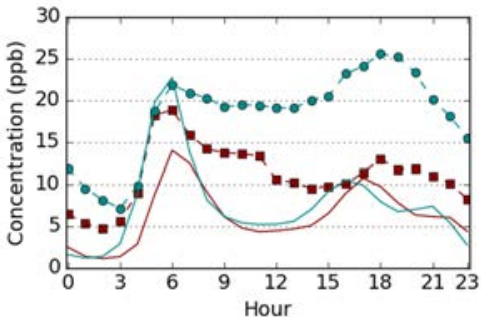

(b)

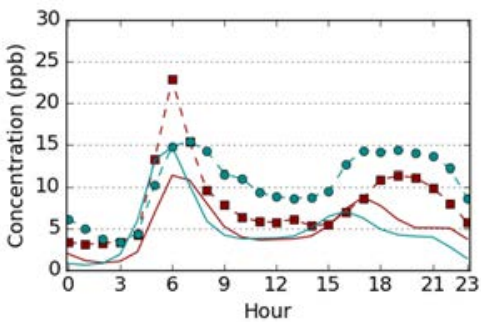

(d)

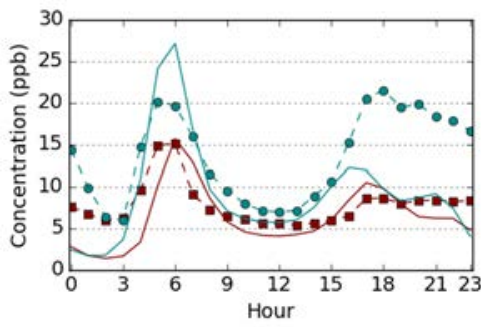

(f)

Observed-dry $\quad$ Modeled-dry $\bullet$ Observed-wet $\quad$ Modeled-wet

Figure 4: Comparison of hourly variation of modeled (solid lines) and observed (dashed lines) $\mathrm{NO}_{2}$ concentrations at the stations in: (a) ACM; (b) Barros Reis; (c) Campo Grande; (d) Itaigara; (e) Paralela; and (f) Pirajá.

Table 4: Statistics comparing modeled and observed $\mathrm{NO}_{2}$ for each air quality station, in ppb units.

\begin{tabular}{ccccccccccc}
\hline \multirow{2}{*}{ ID } & \multicolumn{2}{c}{ OBS } & \multicolumn{2}{c}{ MOD } & \multicolumn{2}{c}{ RMSE } & \multicolumn{2}{c}{ NMB } & \multicolumn{2}{c}{ r } \\
\cline { 2 - 12 } & Dry & Wet & Dry & Wet & Dry & Wet & Dry & Wet & Dry & Wet \\
\hline a & 10.04 & 21.65 & 6.00 & 6.94 & 5.47 & 17.80 & -0.40 & -0.67 & 0.56 & 0.23 \\
\hline b & 11.05 & 18.31 & 6.20 & 7.53 & 6.18 & 13.45 & -0.44 & -0.59 & 0.64 & 0.32 \\
\hline c & 6.98 & 13.39 & 2.37 & 1.77 & 6.10 & 13.32 & -0.67 & -0.87 & 0.45 & 0.13 \\
\hline d & 8.03 & 10.31 & 5.07 & 4.94 & 5.43 & 7.89 & -0.37 & -0.52 & 0.67 & 0.35 \\
\hline e & 13.50 & 11.06 & 6.62 & 7.70 & 8.44 & 6.89 & -0.51 & -0.30 & 0.36 & 0.29 \\
\hline f & 7.80 & 13.55 & 6.29 & 9.04 & 4.12 & 9.77 & -0.19 & -0.33 & 0.47 & 0.36 \\
\hline
\end{tabular}

$\mathrm{NO}_{2}$ : nitrogen dioxide; ppb units: parts per billion units. 
As meteorology and topography play an important role over the MRS, and since the region experiences the influence of sea breezes that possibly aid to disperse the air pollutants concentrations, it is worth mentioning that the evaluation of this work was also done using monitoring stations which represented single points within a whole region, but do not exclude the possibility of having areas where the concentrations exceed the air quality standards.

The discrepancies found between the observed and modeled data can be attributed to the poor representation of the emissions inventories; and the deficiencies in periodic maintenance and bad location of the monitoring stations, the latter by reason of growing industrialization and urbanization over the MRS. Furthermore, it would be necessary to include monthly, daily and weekly variability of the emissions; and to improve the chemical speciation profiles. It is also fundamental to perform experimental campaigns, in order to evaluate the vertical profiles, especially of secondary pollutants. Nevertheless, we found that the CMAQ model was able to represent the hourly and daily variability of the air pollutants at the surface, despite having some large variances.

\section{ACKNOWLEDGEMENTS}

The authors thank the Supercomputing Center for Industrial Innovation (YemojaCIMATEC), the FAPESB, the NQualiAr of UFES, and also the Coordenação de Aperfeiçoamento de Pessoal de Nível Superior (CAPES) for granting the PhD scholarship to the first author.

\section{REFERENCES}

[1] Vormittag, E.M.P.A., Costa, R.R., Braga, A.A., Miranda, M., Nascimento, N.C. \& Saldiva, P.H.N., Monitoramento da Qualidade do Ar no Brasil (Monitoring of Air Quality in Brazil). Instituto Saúde e Sustentabilidade (Institute of Health and Sustainability), 2014.

[2] Alonso, M.F. et al., An urban emissions inventory for South America and its application in numerical modeling of atmospheric chemical composition at local and regional scales. Atmos. Environ., 44, pp. 5072-5083, 2010.

DOI: 10.1016/j.atmosenv.2010.09.013.

[3] CONAMA, Environmental National Committee, New national air quality standards, Resolution number 491/2018. www2.mma.gov.br/port/conama/legiabre.cfm? codlegi=740. Accessed on: 5 Feb. 2019.

[4] Borrego, C. et al., Modelling the photochemical pollution over the metropolitan area of Porto Alegre, Brazil. Atmos. Environ., 44, pp. 370-380, 2010.

DOI: 10.1016/j.atmosenv.2009.10.027

[5] Gidhagen, L. et al., Experimental and model assessment of PM2.5 and BC emissions and concentrations in a Brazilian city: The Curitiba case study. Atm. Chem. Phys. Dis., 2018. DOI: 10.5194/acp-2018-1094.

[6] Albuquerque, T.T.A. et al., WRF-SMOKE-CMAQ modeling system for air quality evaluation in São Paulo megacity with a 2008 experimental campaign data. Env. Sci. Pollut. Res., 25, pp. 36555-36569, 2018. DOI: 10.1007/s11356-018-3583-9.

[7] Gavidia-Calderón, M., Vara-Vela, A., Crespo, N.M. \& Andrade, M.F., Impact of timedependent chemical boundary conditions on tropospheric ozone simulation with WRFChem: An experiment over the Metropolitan Area of São Paulo. Atmos. Env., 195, pp. 112-124, 2018. DOI: 10.1016/j.atmosenv.2018.09.026.

[8] Pedruzzi, R. et al., Performance evaluation of a photochemical model using different boundary conditions over the urban and industrialized metropolitan area of Vitória, Brazil. Env. Sci. Pollut. Res., 2019. DOI: 10.1007/s11356-019-04953-1. 
[9] Skamarock, W.C. et al., A Description of the Advanced Research WRF Version 3. National Center for Atmospheric Research, 2008.

[10] National Centers for Environmental Prediction (NCEP)/National Weather Service/ National Oceanic and Atmospheric Administration (NOAA)/U.S. Department of Commerce. Updated daily. GDAS/FNL 0.25 degree global tropospheric analyses and forecast grids. Research data archive at the National Center for Atmospheric Research, Computational and Information Systems Laboratory.

DOI: $10.5065 / \mathrm{D} 65 \mathrm{Q} 4 \mathrm{~T} 4 \mathrm{Z}$.

[11] Kitagawa, Y.K.L., Nascimento, E.G.S., De Souza, N.B.P., Moreira, S., Albuquerque, T.T.A. \& Moreira, D.M., Evaluation of the chemical transport of air pollutants in the metropolitan region of Salvador, Brazil. WIT Transactions on Ecology and the Environment, vol. 230, WIT Press: Southampton and Boston, pp. 519-530, 2018. DOI: $10.2495 / A I R 180481$.

[12] Crippa, M. et al., Gridded emissions of air pollutants for the period 1970-2012 within EDGAR v4.3.2. Earth Syst. Sci. Data, 10, pp. 1987-2013, 2018. DOI: $10.5194 /$ essd-10-1987-2018.

[13] Guenther, A.B. et al., The model of emissions of gases and aerosols from nature version 2.1 (MEGAN2.1): An extended and updated framework for modeling biogenic emissions. Geosci. Model Dev., 5, pp. 1471-1492, 2012.

DOI: $10.5194 /$ gmd-5-1471-2012.

[14] Lyra, D.G.P., Modelo Integrado de Gestão de Qualidade do Ar da região Metropolitana de Salvador (Integrated Model of Air Quality for the Metropolitan Region of Salvador). PhD thesis, State University of Campinas, São Paulo, Brazil, 2008.

[15] Byun, D. \& Schere, K.L., Review of the governing equations, computational algorithms, and other components of the Models-3 community multiscale air quality (CMAQ) modeling system. Appl. Mech. Rev., 59(2), pp. 51-77, 2006.

DOI: $10.1115 / 1.2128636$.

[16] Carpenter, M.L. \& Nokleby, J., In-stack measurement of $\mathrm{NO}_{2}$ partitions from various combustion sources. Presented at Annual Meeting for the Environmental Professionals of Arizona, Scottsdale, AZ, USA, 2012. 